\title{
Alteration of Decreased Plasma NO Metabolites and Platelet NO Synthase Activity by Paroxetine in Depressed Patients
}

\author{
Wendy Chrapko', Paul Jurasz ${ }^{2,4}$, Marek W Radomski, ${ }^{2,4}$, Stephen L Archer ${ }^{3}$, Stephen C Newman', \\ Glen Baker', Nathalie Lara' and Jean-Michel Le Mellédo*,' \\ 'Department of Psychiatry, University of Alberta, Edmonton, AB, Canada; ${ }^{2}$ Department of Pharmacology, University of Alberta, Edmonton, \\ $A B$, Canada; ${ }^{3}$ Department of Medicine and Physiology, University of Alberta, Edmonton, $A B$, Canada
}

\begin{abstract}
Although major depression (MD) and cardiovascular disease (CVD) have been conclusively linked in the literature, the mechanism associating $M D$ and CVD is yet undetermined. The purpose of this paper is to further investigate a potential mechanism involving nitric oxide (NO) and to examine the effect of the selective serotonin reuptake inhibitor paroxetine on NO production by both platelets and the endothelium. In total, 17 subjects with MD and 12 healthy controls (HCs) with no known history of cardiovascular illness completed the study. Paroxetine was administered to both the MD patients and HCs over an 8-week period, and then medication was discontinued. Blood samples were taken at various times throughout paroxetine treatment and after discontinuation. Plasma NO metabolite ( $N O x$ ) levels were measured by a chemiluminescence method. Platelet endothelial NO synthase (eNOS) activity was examined through the conversion of $\mathrm{L}-\left[{ }^{14} \mathrm{C}\right]$ arginine to $\mathrm{L}-\left[{ }^{14} \mathrm{C}\right]$ citrulline. Data were analyzed using $t$-tests and a linear mixed effects model. Baseline levels of both plasma NOx and platelet NOS activity were significantly lower in subjects with MD compared to HCs. Throughout paroxetine treatment, plasma NOx levels increased in both HCs and MD patients. However, platelet eNOS activity decreased in HCs, while no statistically significant change was evidenced in MD patients. These data suggest that, in MD patients, decreased peripheral production of $\mathrm{NO}$, a potential contributor to increased cardiovascular risk, is modified by administration of the antidepressant paroxetine. Neuropsychopharmacology (2006) 3I, I286- 1293. doi:I 0.1038/sj.npp. I 30096I; published online 23 November 2005
\end{abstract}

Keywords: major depression; nitric oxide; cardiovascular risk; endothelium function; platelet; paroxetine

\section{INTRODUCTION}

The link between major depressive disorder (MD) and cardiovascular disease (CVD) has been well established. In prospective studies using initially physically healthy subjects, MD has been found to be an independent risk factor for both first myocardial infarction and cardiovascular (CV) mortality, with a range of 1.5-2 for adjusted relative risk (Rudisch and Nemeroff, 2003). In addition, patients suffering from CVD who are also diagnosed with MD have a 2.5- to 4-fold increase in the occurrence of CV events (Rozanski et al, 1999). Although the biological mechanisms underlying the relationship between MD and CVD remains

\footnotetext{
*Correspondence: Dr J-M Le Mellédo, Department of Psychiatry, University of Alberta, IE7.05 Walter C Mackenzie Health Sciences Centre, 8440-112 Street, Edmonton, AB, Canada T6G 2B7, Tel: + I 780407 3906, Fax: + I 7804076672 ,

E-mail: jean-michel.lemelledo@ualberta.ca

${ }^{4}$ Current address: Department of Integrative Biology and Pharmacology and Institute of Molecular Medicine, University of Texas-Houston, Houston, TX, USA

Received 20 April 2005; revised 9 September 2005; accepted 29 September 2005

Online publication: 12 October 2005 at http://www.acnp.org/citations/ Npp I01205050263/default.pdf
}

to be identified, endothelial dysfunction, platelet hyperactivity, and hypothalamic-pituitary-adrenocortical axis (HPA) hyperactivity have been suggested as the main mechanistic explanations for the link between MD and CVD (Joynt et al, 2003).

Recent studies allude to a potential role of nitric oxide (NO) in the relationship between MD and CV risk as well as an effect of antidepressants on NO production (Rajagopalan et al, 2001; Finkel et al, 1996; Lara et al, 2003a). NO produced from either the endothelium or from platelets plays a major role in $\mathrm{CV}$ regulation and $\mathrm{CV}$ pathology. Indeed, numerous $\mathrm{CV}$ diseases, such as hypertension, heart failure, and coronary artery disease, have been associated with alterations in the NO system (Moncada and Higgs, 1993). NO is not only responsible for vasodilatation of the endothelium but also inhibits smooth muscle cell proliferation and migration, oxidation of low-density lipoproteins, and platelet aggregation and adhesion. It also disaggregates preformed platelet aggregates (Radomski et al, 1987) and inhibits activated platelet recruitment to the aggregate (Freedman et al, 1997). NO is synthesized from L-arginine by a family of isoformic enzymes known as nitric oxide synthase (NOS). Three isoforms, namely endothelial, neuronal, and inducible NOS (eNOS, nNOS, and iNOS, respectively), have been identified. The eNOS isoform has 
been found not only in the endothelium, after which it was named, but also in platelets (Mehta et al, 1995; Radomski et al, 1990). Endothelial dysfunction precedes overt vascular disease, even in the first decade of life (Shimokawa, 1999). Furthermore, certain polymorphisms of the eNOS gene have been shown to predispose to acute coronary syndrome (Fatini et al, 2004).

Levels of plasma NO metabolites (NOx) have been used as markers for endothelial NO production (Archer, 1993). It has also been suggested that impaired platelet production of NO can predict the presence of acute coronary syndromes (Freedman et al, 1998). Platelet eNOS activity can be measured in homogenized platelet pellets (Radomski and Moncada, 1983; Radomski et al, 1993).

In recent years, selective serotonin reuptake inhibitors (SSRIs) have become the most commonly prescribed treatment for $\mathrm{MD}$, particularly in a population with comorbid depression and CV disease (Roose, 2003). Finkel et al (1996) found that in subjects with ischemic heart disease being treated for $\mathrm{MD}$, the SSRI paroxetine reduced levels of NO, suggesting a potentially deleterious effect of paroxetine on the $\mathrm{CV}$ system since decreased endothelium production of NO is usually associated with increased CV risk (Drexler and Hornig, 1999). However, numerous studies have found that SSRIs, including paroxetine, are a safer treatment option in a population with CVD and MD in comparison to tricyclic antidepressants (Roose et al, 1998; Roose and Spatz, 1999; Glassman et al, 2002).

Intrigued by the finding of Finkel et al (1996), our research team investigated the effects of paroxetine on plasma NOx levels in a group of male healthy controls (HCs) (Lara et al, 2003a). In that study, administration of paroxetine resulted in an increase in plasma NOx levels after 8 weeks of administration. This is particularly interesting as we have also shown, in a separate study, that plasma NOx levels and platelet eNOS activity are extremely low in unmedicated MD patients without conventional CV risk factors (Chrapko et al, 2004). It has also been shown, by other researchers, that 6 weeks of paroxetine normalized increased platelet reactivity in MD patients (Musselman et al, 2000). This effect could be mediated by a paroxetineinduced increase in platelet eNOS activity since the $\mathrm{L}$-arginine-NO pathway is a negative feedback mechanism to suppress excessive platelet activation and aggregation (Radomski and Moncada, 1993). An increase in endothelial and platelet NO production by treatment with paroxetine could have a potentially cardioprotective effect in patients with MD.

The aim of our current study was to investigate the effects of paroxetine on the production of $\mathrm{NO}$ by the endothelium and platelets in both male and female patients suffering from MD or HCs. We hypothesized that both plasma NOx levels and platelet eNOS activity will increase after administration of paroxetine in both subject groups.

\section{MATERIALS AND METHODS}

\section{Subjects Design and General Procedures}

Subjects were $12 \mathrm{HCs}$ (seven males and five females, mean age $26.75 \pm 2.78$ years) and 17 patients diagnosed with current MD (11 males and six females, mean age $34.50 \pm 2.08$ years).
All subjects were assessed using the Structured Clinical Interview for DSM-IV Axis I Disorders. No HCs were diagnosed with either current or past psychiatric Axis I disorder. MD patients with a diagnosis of comorbid anxiety disorder, but no other Axis I disorder such as bipolar disorder or schizophrenia, were included because of the frequency of comorbidity (Rapaport, 2001). In these patients, the diagnosis of MD was always the primary diagnosis. The mean score on the Hamilton Depression Rating Scale (Hamilton, 1960) for the MD patients was $20.71 \pm 4.25$ and on the Beck Depression Inventory (Beck et al, 1961) the mean score was $25.18 \pm 4.08$, indicating that most patients were in the moderate range of severity. All MD patients were free of psychotropic medications for at least 1 year. Classical CV risk factors (blood pressure, cholesterol levels, and physical activity) were measured at baseline. Physical activity levels were measured using the seven-day recall interview (Blair et al, 1985).

One male MD patient was a smoker and consistently smoked approximately half a pack of cigarettes per day. Since acute smoking directly affects NOx plasma levels (Tsuchiya et al, 2002), he was asked to refrain from smoking prior to any visit where blood samples were taken. It was also established that subjects did not have current or past CVD or a family history of early cerebrocardiovascular illness.

In total, 40 subjects ( $16 \mathrm{HCs}$ and 24 with MD) began the study. Of the HCs, one (male) withdrew due to time constraints and three HCs (two males and one female) withdrew due to side effects (anorgasmia for both males and nausea for the female). Of the MD subjects, five subjects with MD (one female and four males) were withdrawn from the study due to noncompliance (eg, missing appointments or irregular use of medications). One female MD patient withdrew after the screening due to extremely high levels of anxiety. Another female MD patient was withdrawn due to her very irregular menstrual cycles, which made the accurate and regular scheduling of her appointments according to her menstrual cycle (see below) impossible. All subjects gave written consent after receiving a full written and verbal explanation of the study. Ethics approval was obtained from the Health Research Ethics Board at the University of Alberta prior to the commencement of the study. The investigation was conducted in accord with the Helsinki Declaration.

Each subject came in for a total of seven visits, which corresponded to a baseline visit, visits after 1, 2, 4, 6, and 8 weeks of treatment, and then one visit after discontinuation of the medication. As described below, only at certain visits were blood samples taken. During all visits, side effects of the paroxetine and severity of MD symptoms were systematically assessed. Experimental design in the collection of the NOx blood samples varied slightly between male and female subjects, due to the need to control for menstrual cycle, as different phases of the menstrual cycle can effect circulating levels of NOx (Cicinelli et al, 1996). For both MD and HC males, venous blood samples were taken at baseline, after 2 weeks, 6 and 8 weeks of treatment, and between 8 and 12 days after discontinuation of paroxetine. For both MD and HC females, venous blood samples were taken at baseline, after 8 weeks of treatment, and again after discontinuation for one full menstrual cycle with all visits 
scheduled prior to midcycle, as NOx levels peak during this time of the menstrual cycle (Cicinelli et al, 1996). Owing to the large amount of blood required (approximately $40 \mathrm{ml}$ ) and the time-intensive nature of the NOS assay, for both males and females, venous blood samples for the analysis of platelet activity were collected only at baseline and after 8 weeks of treatment.

Prior to every visit with blood collection, subjects fasted for a minimum of $12 \mathrm{~h}$ and followed a low nitrate diet for 3 days, to control for the confounding effects of dietary nitrate (Viinikka, 1996). Subjects were also asked to refrain from taking any medication for 3 days prior to sampling as various commonly taken medications, such as ibuprofen, have been shown to alter NO production (Vandivier et al, 1999).

During the baseline visit, paroxetine was provided, with treatment to start the following day. Paroxetine was administered initially at a dose of $10 \mathrm{mg} /$ day for 3 days and then increased to $20 \mathrm{mg} / \mathrm{day}$ for the remainder of the study. Side effects were frequently reported and were those generally associated with the administration of SSRIs, such as nausea, changes in bowel movements, and sexual dysfunction. However, these were tolerated well by both the MD patients and HCs who completed the study. Discontinuation of the medication was gradual to prevent withdrawal effects, and tapered to $10 \mathrm{mg} /$ day for 5 days, then stopped.

\section{Platelet Isolation}

The method for platelet isolation was performed as described previously by Radomski and Moncada (1983). Briefly, $36 \mathrm{ml}$ of peripheral venous blood from the antecubital vein was added to $4 \mathrm{ml}$ of $3.15 \%(\mathrm{w} / \mathrm{v})$ trisodium citrate. Prostacyclin $\left(\mathrm{PGI}_{2}, 0.3 \mathrm{mM}\right)$ was added to the citrated blood, which was then centrifuged at $250 \mathrm{~g}$ for $20 \mathrm{~min}$. To obtain the platelet pellet, the platelet-rich plasma (upper layer) was then collected and further centrifuged at $900 \mathrm{~g}$ in the presence of $1 \mathrm{mM} \mathrm{PGI}$. Platelets were then gently resuspended in Tyrode's buffer to leave behind contaminating red blood cells, and the platelet suspension was centrifuged at $900 \mathrm{~g}$ in the presence of $1 \mathrm{mM} \mathrm{PGI}_{2}$. The platelet pellet was then washed three times with Tyrode's solution $(1 \mathrm{ml})$ and frozen at $-80^{\circ} \mathrm{C}$ until assayed for NOS activity.

\section{Determination of Platelet NOS Activity}

eNOS activity was measured using the method of Radomski et al (1993). Briefly, the platelet pellets were homogenized on ice using a Vibra Sonic sonicator (Sonics \& Materials Inc., Danbury, CT). The conversion of $\mathrm{L}_{-}\left[{ }^{14} \mathrm{C}\right]$ arginine to $\mathrm{L}-\left[{ }^{14} \mathrm{C}\right]$ citrulline was used as a measure of platelet eNOS activity. The dependence of L-arginine conversion on $\mathrm{Ca}^{2+}$ dependent (constitutive) NOS was confirmed using EGTA and $N(G)$-mono-methyl-L-arginine (L-NMMA), an inhibitor of this enzyme. The sensitivity of this assay has been shown to be just under $1 \mathrm{pmol} / \mathrm{min} / \mathrm{mg}$ protein for the detection of $\mathrm{L}-\left[{ }^{14} \mathrm{C}\right]$ arginine. The isoform specificity of this analysis is demonstrated through the use of the calcium chelator EGTA, which allows us to fractionate calcium-independent (iNOS) activity $v s$ general NOS activity (inhibited by L-
NMMA). In addition, any nonspecific conversion of $\mathrm{L}-\left[{ }^{14} \mathrm{C}\right]$ arginine is subtracted. Using these controls, we detected no iNOS activity in any of the samples, in keeping with its extremely low induction rate and expression in individuals that are free of inflammatory disease.

\section{Determination of NO Metabolite Levels}

Peripheral venous blood samples were collected into a $5 \mathrm{ml}$ vacutainer tube containing EDTA and immediately centrifuged (at $3000 \mathrm{RPM}$ at $4{ }^{\circ} \mathrm{C}$ for $10 \mathrm{~min}$ ) to isolate the plasma.

All samples were analyzed using the chemiluminescence method (Archer et al, 1998). Briefly, NOx in small amounts of plasma can be converted into NO using a strong reducing environment, namely vanadium (III) chloride in $1 \mathrm{~N} \mathrm{HCl}$ at $93.3^{\circ} \mathrm{C}$, and can then be detected by an NO Analyser (NO Analyser 280; Sievers Instruments, Boulder, CO). The sensitivity of this analyser is $\sim 1 \mathrm{pM}$ of $\mathrm{NO}$ injected into the purge vessel. This analysis will convert almost all nitrate and nitrite to NO, and thus the importance of a nitrate-free diet. Plasma samples were diluted with an equal volume of double deionized NO-free water to decrease sample viscosity. An antifoaming agent (Dow Corning, Midland, MI) was added to the reagent to avoid foaming caused by plasma proteins. NOx levels are reported in $\mu \mathrm{mol} / \mathrm{l}$.

\section{Determination of Paroxetine Levels}

To monitor compliance, a blood sample was taken at 8 weeks into treatment to measure plasma paroxetine levels in both males and females. Subjects had taken the paroxetine at between 1.5 and $3 \mathrm{~h}$ prior to collection of the blood sample and thus were in the absorption phase at the time of sampling. Plasma paroxetine levels were analyzed using the gas chromatographic procedure of Lai et al (2000). Briefly, this involves basification of the samples, extraction with ethyl acetate, derivatization with heptafluorobutyric anhydride, and analysis on a gas chromotograph (Hewlett Packard 5890) equipped with a capillary column and an electron-capture detector.

\section{Statistical Analysis}

An independent samples $t$-test was used to determine if there were significant differences between baseline plasma NOx levels and platelet eNOS activity in the HCs and subjects with MD. Since either heavy or light chronic smoking influences NO production (Barua et al, 2002), for this analysis the male MD patient who smoked was excluded from this analysis. In addition, NOx levels were not obtained from one MD subject and NOS levels were not obtained from another MD subject due to difficulties in drawing the blood samples.

For the statistical analysis of differences in plasma NOx levels, a linear mixed effects model (Vonesh and Chinchilli, 1997) was used. Random and fixed effects were entered as linear expressions, and time, measured in weeks from baseline, was treated as a continuous variable. This model has advantages over classical linear regression and repeated measures analysis of variance: intra- as well as interindividual variation can be modelled, correlated observations can be analyzed, and missing data are permitted. Both a random 
intercept and a random slope model were fit to the data. The statistical analysis was performed using the SAS procedure PROC NLMIXED (SAS Institute Inc., 1999). To confirm these results using a more traditional approach, a weighted linear regression was performed, with adjustments made for correlated observations. Post hoc analyses in the form of paired $t$-tests were conducted to determine when changes in NO $x$ levels became significantly different from baseline and to compare baseline blood samples to those taken after discontinuation of paroxetine.

For the statistical analysis of platelet eNOS activity, a twoway ANOVA was used to measure the differences between baseline visits and after 8 weeks of treatment for all subjects with data for both visits, namely $16 \mathrm{MD}$ subjects and 11 HCs. A post hoc within-subjects $t$-test was performed to examine the significance of changes between baseline and end of treatment measurements. Finally, an independent samples $t$-test was performed to determine if there was a statistically significant difference between the MD patients and HCs for the samples drawn after 8 weeks of treatment.

Owing to a very low plasma level of paroxetine in one subject taken during the visit 8 weeks into treatment, this subject was excluded from the analysis, other than the portion listed below, as he may have not been following the proper treatment regimen. However, this particular subject might have been an ultrarapid (Sindrup et al, 1992). The subject in question was included in the baseline samples analysis (prior to treatment) and included in the mixed effects model for the analysis of plasma NOx levels. Results remained statistically significant whether this subject was included in or excluded from the mixed effects models.

In the initial weighted linear regression and mixed effects analyses, the one male MD patient who was also a smoker was included. Removal of this patient from a subsequent analysis had no discernable effect on the results (not shown). An independent samples $t$-test was used to determine if there were any significant differences between the HCs and MD patients with regard to a variety of factors that have been known to affect NO production.
Unless otherwise indicated, statistical analyses were conducted using SPSS statistical software for windows (SPSS Inc., Chicago, IL). Values are expressed as means \pm standard deviations. A $p$-value of less than 0.05 was considered significant in all analyses.

\section{RESULTS}

Baseline plasma NOx levels were lower in MD patients compared to HCs $(5.74 \pm 6.01$ and $23.33 \pm 13.01 \mu \mathrm{mol} / \mathrm{l}$, respectively, $\mathrm{t}=4.75, \mathrm{df}=25, p<0.001)$ and baseline platelet eNOS activity was also decreased in MD patients compared to HCs $(1.25 \pm 1.33 \mathrm{pmol} / \mathrm{min} / \mathrm{mg}$ protein $v s$ $16.41 \pm 9.68 \mathrm{pmol} / \mathrm{min} / \mathrm{mg}$ protein, respectively, $\mathrm{t}=6.23$, $\mathrm{df}=25, p<0.001)$.

Figure 1 shows plasma NOx levels in MD patients and HC subjects. At each observation time, plasma NOx levels are lower in MD patients as compared to HCs. Mixed effects models were fit with NOx level as the dependent variable and with fixed effects for study group (modelled as dummy variable: $1=\mathrm{MD} ; 0=\mathrm{HC}$ ), time squared, age and gender, and with random effects for intercept and slope. The final model was a random intercept model with terms for study group and time squared (Table 1); an interaction term for study group and time was not statistically significant. The weighted linear regression analysis produced a final model with the same (fixed) effects, having almost identical parameter estimates, but with somewhat smaller $p$-values.

Paroxetine treatment progressively increased plasma NOx levels in both HCs and MD patients (Figure 1). Since there was no interaction between study group and time on plasma NO $x$ samples, evidenced by the lack of significance of an interactive term in the random intercept model, the HCs and MD patients were grouped together for post hoc analysis aimed at determining the chronology of the increases from baseline in plasma NOx levels induced by paroxetine. Plasma levels of NOx were significantly increased, compared to baseline, after 2 weeks $(t=-2.23$,

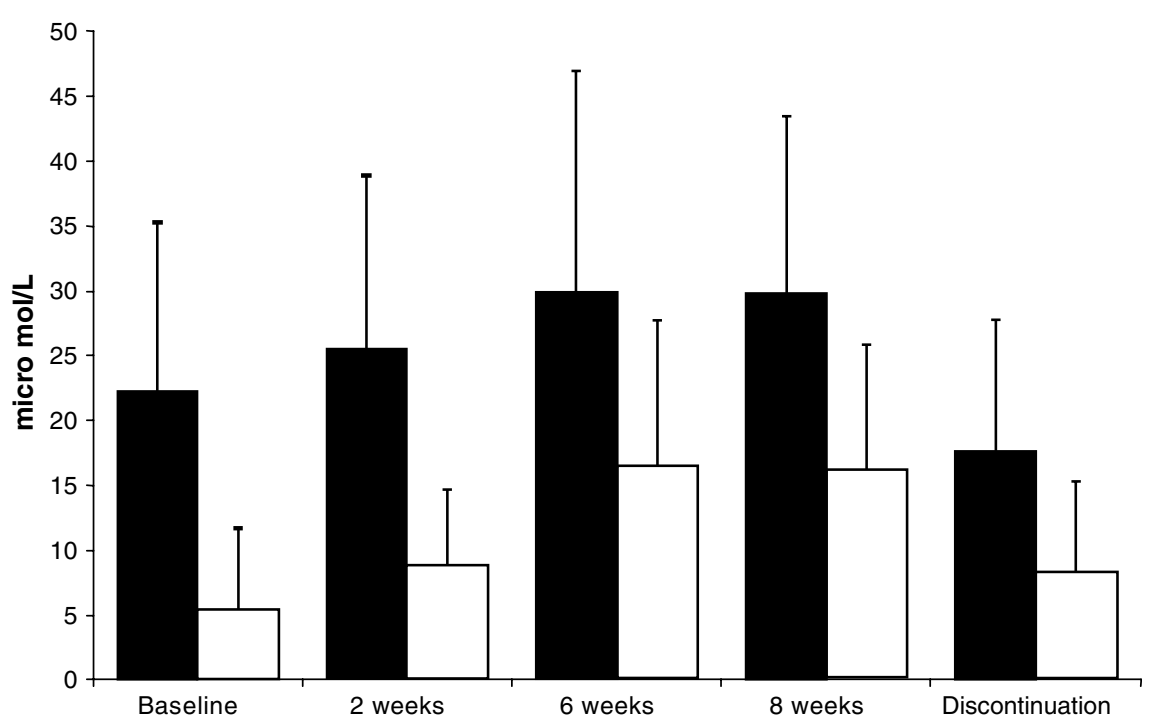

Figure I Plasma nitric oxide metabolite levels in major depressive patients (MD) compared to healthy controls (HC). Black bars represent $\mathrm{HC}$ and open bars represent MD patients. 
$\mathrm{df}=15, p=0.04), 6$ weeks, and 8 weeks of treatment $(\mathrm{t}=-3.22, \quad \mathrm{df}=16, \quad p=0.005$ and $\mathrm{t}=-5.68, \quad \mathrm{df}=26$, $p<0.01$, respectively). There was no statistically significant difference between measures at baseline and after discontinuation of the paroxetine $(\mathrm{t}=0.35, \mathrm{df}=23, p=0.73)$, suggesting that after paroxetine discontinuation plasma $\mathrm{NO} x$ levels return to pretreatment levels. In both the MD patients and HCs, there appears to be a plateauing of the plasma NOx levels in that there is no longer a statistically significant difference in the means between the 6 and 8 week visits $(\mathrm{t}=-0.48, \mathrm{df}=16, p=0.64)$.

Based on the analysis of platelet NOS activity in all patients, a main effect for time and a time by study group effect was found $(\mathrm{F}=37.43, \mathrm{df}=1, p<0.001$ and $\mathrm{F}=21.43$, $\mathrm{df}=1, \quad p<0.001$, respectively; see Figure 2). Post hoc analysis indicated that there was a significant decrease in platelet NOS activity in the $\mathrm{HCs}$, from $16.41 \pm 9.68 \mathrm{pmol} /$ $\mathrm{min} / \mathrm{mg}$ protein at baseline to $1.62 \pm 1.55 \mathrm{pmol} / \mathrm{min} / \mathrm{mg}$ protein after 8 weeks of paroxetine treatment $(t=6.23$, $\mathrm{df}=25, \quad p=<0.001)$. The increase in platelet eNOS platelet activity was not statistically significant in the MD group $(1.25 \pm 1.33 \mathrm{pmol} / \mathrm{min} / \mathrm{mg}$ protein at baseline $v s$

Table I Analysis Using the Linear Mixed Effects Model for NOx Levels in MD Compared to HC

\begin{tabular}{lrcrr}
\hline Parameter & Estimate & Standard Error & t-value & p-value \\
\hline Fixed effects & & & & \\
Intercept & 31.46 & 2.80 & 11.26 & $<0.0001$ \\
MD & -14.27 & 3.32 & -4.29 & 0.0002 \\
Time squared & -0.41 & 0.07 & -5.95 & $<0.001$ \\
& & & & \\
Random effect & & & & \\
Intercept & 60.25 & 19.80 & 3.04 & 0.0053 \\
\hline
\end{tabular}

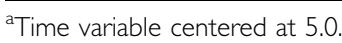

$2.50 \pm 3.64 \mathrm{pmol} / \mathrm{min} / \mathrm{mg}$ protein after 8 weeks of paroxetine treatment, $\mathrm{t}=-1.24, \mathrm{df}=15, p=0.233)$. There was also no statistically significant difference in platelet NOS activity between the MD patients and $\mathrm{HCs}$ after 8 weeks of treatment $(\mathrm{t}=-0.75, \mathrm{df}=25, p=0.461)$.

Response to paroxetine in MD patients was classically defined by at least a $50 \%$ improvement on the Hamilton Depression Rating Scale score. There were no apparent differences in plasma NOx levels and platelet NOS activity between responders $(n=11)$ and nonresponders $(n=6)$ $(\mathrm{t}=-0.75, \mathrm{df}=14, p=0.89$ and $\mathrm{t}=-0.53, \mathrm{df}=14, p=0.60$, respectively).

Using Pearson's correlation coefficient, we did not find a correlation between platelet NOS activity and plasma NOx levels in HCs after 8 weeks of treatment (correlation coefficient $=-0.56, p=0.79$ ).

No significant differences were found between the HCs and MD patients with regard to a variety of factors that have been known to affect NO production and thus may have confounded the results (see Table 2).

\section{DISCUSSION}

The lower baseline plasma NOx levels observed in MD patients suggest that the production of $\mathrm{NO}$ by the endothelium is decreased in MD patients. Endothelium dysfunction (of which a prominent component is the reduced availability of endothelial NO) is a well-established predictor of development of overt CVD. Our results suggest that a decreased endothelial NO production is a possible major contributing factor to the increased risk for CVD associated with MD. The dramatic decrease in baseline platelet eNOS activity that we observed likely contributes to the platelet hyperactivity found in MD patients, one of the main mechanistic hypotheses for the increased CV risk in MD (Joynt et al, 2003).

The HPA axis hyperactivity described in MD patients (Plotsky et al, 1998) represents a potential mechanism

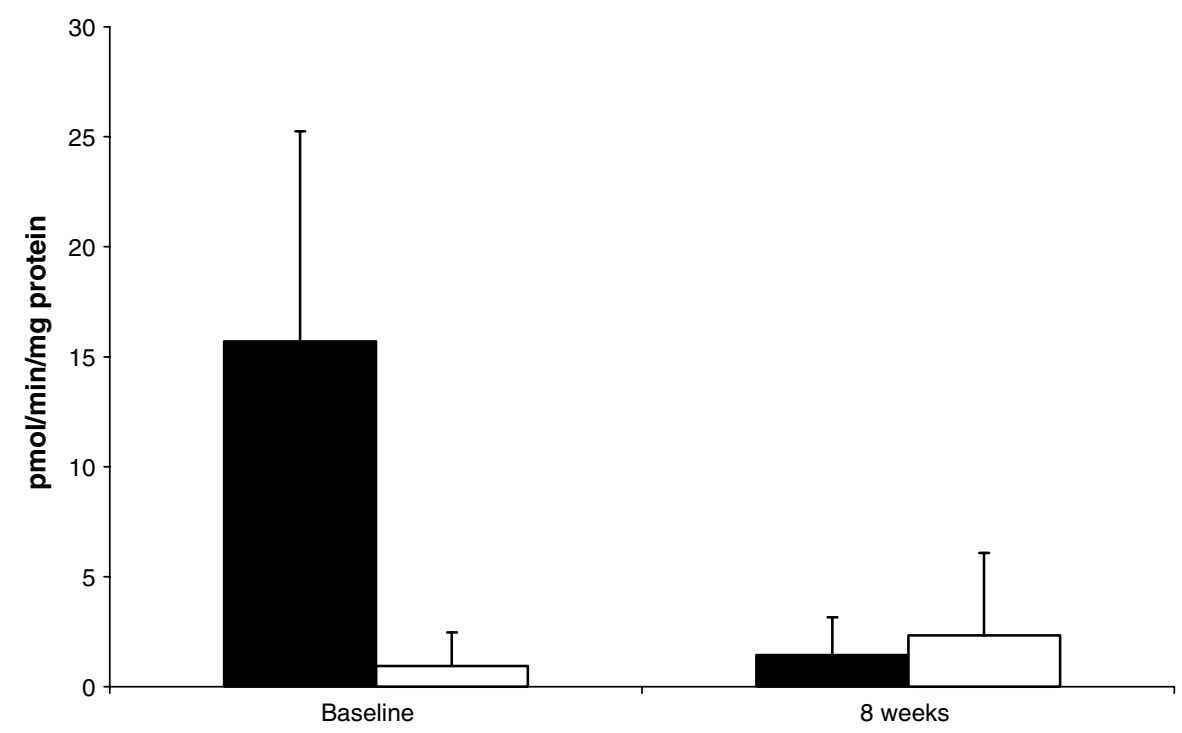

Figure 2 Platelet nitric oxide synthase activity, at baseline and after 8 weeks of paroxetine treatment, in patients with major depression (MD) compared to healthy controls (HCs). Black bars represent HCs and open bars represent MD patients. 
Table 2 Demographic and Laboratory Values in Study Subjects

\begin{tabular}{|c|c|c|c|c|c|}
\hline Patient characteristic & MD & $\mathrm{HC}$ & t-value & df & $p$-value \\
\hline Physical activity (kcal/kg/day) & $35.04( \pm 3.43)$ & $35.45( \pm 1.99)$ & 0.37 & 27 & 0.72 \\
\hline LDL-cholesterol (mg/l) & $120.96( \pm 44.26)$ & $102.73( \pm 34.89)$ & -1.19 & 27 & 0.25 \\
\hline HDL-cholesterol (mg/l) & $43.96( \pm 11.13)$ & $48.52( \pm 7.80)$ & -1.22 & 27 & 0.23 \\
\hline Total cholesterol (mg/l) & $198.53( \pm 36.95)$ & $171.87( \pm 31.94)$ & -2.02 & 27 & 0.06 \\
\hline Triglycerides (mg/l) & $136.07( \pm 64.59)$ & $100.87( \pm 35.7 \mid)$ & -1.71 & 27 & 0.10 \\
\hline $\mathrm{SBP}(\mathrm{mmHg})$ & $120.50( \pm 12.74)$ & $119.36( \pm 13.15)$ & -0.23 & 25 & 0.82 \\
\hline $\mathrm{DBP}(\mathrm{mmHg})$ & $79.25( \pm 8.58)$ & $78.64( \pm 13.24)$ & -0.15 & 25 & 0.89 \\
\hline
\end{tabular}

$\mathrm{MD}=$ patients with major depression; $\mathrm{HCs}=$ healthy controls; $\mathrm{BMI}=$ body mass index; $\mathrm{SBP}=$ systolic blood pressure; $\mathrm{DBP}=$ diastolic blood pressure; $\mathrm{HDL}=$ highdensity lipoprotein; $L D L=$ low-density lipoprotein.

explaining the increased risk of CVD in MD patients. Indeed, cortisol promotes the development of atherosclerosis (Joynt et al, 2003) and has therefore the potential for inducing a decrease in endothelial NO production (Anderson, 2003). Furthermore, it has been shown that glucocorticoids, more particularly cortisol, induce a downregulation of eNOS in endothelial cells as well as a decrease in plasma NOx levels (Wallerath et al, 1999; Rogers et al, 2002). Chronic cortisol administration to healthy human controls is also associated with decreased endothelium-dependent flow-mediated dilatation, which reflects endothelial NO production (Mangos et al, 2000). The HPA axis hyperactivity found in MD could therefore be responsible, at least partially, for the endothelial and platelet NO dysregulations observed in MD patients, which in turn could mediate some of the deleterious CV effects of HPA hyperactivity in MD patients.

The current study confirms results on the effect of paroxetine on plasma NOx levels that we reported in an independent group of male HCs (Lara et al, 2003a). The findings of that study indicated that plasma NOx levels increased significantly after treatment with paroxetine for 8 weeks, then normalized after discontinuation of the medication, suggesting that paroxetine increased endothelial NO production in a reversible manner. In that study, HCs were first tested to avoid the confounding effect of depressive illness and its recovery on NOx measures, allowing the study of pharmacological, $v s$ therapeutic, effect. The current study increases the scope of this previous study on the effect of paroxetine on plasma NOx levels by including female subjects, by studying a relevant patient population, and by studying the chronology of paroxetineinduced increases in plasma NOx levels. The increase in plasma NOx levels was rapid, with a statistically significant increase noted in the first 2 weeks, before the antidepressant effect takes place. Plasma NOx levels appear to reach a plateau in both MD patients and HCs after 6 weeks of paroxetine treatment. A longer time course of treatment would be necessary to assess whether this is a true plateau and whether the paroxetine induced increase in $\mathrm{NO} x$ plasma levels are transient or sustained. Additionally, there were no differences between the MD patients who were responders compared to nonresponders. Altogether, these results demonstrate that the effects of paroxetine on plasma NOx are independent of its antidepressant effect. The hypothesis of a direct effect of paroxetine on peripheral NO production is also favored by the fact that shortly after paroxetine is discontinued, concentrations of plasma $\mathrm{NO} x$ return to their pretreatment level. Our findings, however, do not preclude a role of brain NO in antidepressant activity.

Paroxetine administration led to a $198 \%$ increase in plasma NOx levels in MD patients. By comparison, it has been shown that 8 weeks of chronic exercise training increase plasma NOx by $58 \%$ (Maheda et al, 2001) and that moderate chronic smokers display a $22 \%$ decrease in NOx plasma levels and heavy smokers a 36\% decrease (Node et al, 1997). The magnitude of the effect of paroxetine on plasma NOx levels compared to both CV protective factors and $\mathrm{CV}$ risk factors that impact endothelium function supports the clinical significance of our results.

In this study, we investigated whether paroxetine increases platelet eNOS activity in order to elucidate a possible mechanism for the decrease in platelet activation described after treatment with paroxetine. Indeed, several studies have found that paroxetine and other SSRIs decrease platelet activation in MD patients (Musselman et al, 2000; Serebruany et al, 2001; Pollock et al, 2000; Serebruany et al, 2003), an effect that should be beneficial from a CV point of view. The lack of statistically significant paroxetine-induced increase of platelet eNOS activity in MD patients does not support this hypothesis. However, a paroxetine-induced increase in platelet $\mathrm{NO}$ availability due to a concomitant increase in eNOS protein expression cannot be excluded. A beneficial impact of paroxetine-induced alterations of NO production on platelet function in MD patients is also supported by the fact that endothelium-derived NO (which is reflected by NOx plasma levels), in addition to its vasodilatory properties, also contributes to the regulation of platelet activation, thereby playing a role in the prevention of thrombus formation (Corti et al, 2003). Nevertheless, the SSRI-induced decrease in platelet serotonin uptake likely contributes substantially to SSRI-induced decrease in platelet activity (Serebruany et al, 2003). The decrease of platelet eNOS activity observed in HCs could be interpreted as a homeostatic downregulation in response to the paroxetine-induced excessive increase in NO availability. 
Indeed, exposure of washed human platelets to NO has been shown to induce a compensatory decrease in platelet eNOS activity (Chen and Mehta, 1997).

Our results of a paroxetine-induced increase in plasma $\mathrm{NO} x$ in $\mathrm{MD}$ patients (close to normalization, that is, baseline levels in HCs) suggest that paroxetine administration improves endothelium function in MD patients and may therefore reduce the $\mathrm{CV}$ risk associated with MD. Interestingly, cardiac drugs that improve outcome in atherosclerosis (eg statins, angiotensin-converting inhibitors) also improve endothelial function (Laroia et al, 2002; Bonetti et al, 2003).

However, the direct physiological impact of the paroxetine-induced increases in endothelial NO production that our results suggest should be confirmed. Measurement of the endothelium-dependent flow-mediated dilation of the brachial artery with ultrasonography is one of the methods that may serve to confirm that paroxetine-induced increase in plasma NOx levels is associated with an improvement in endothelial function (Sauer et al, 2003; Faulx et al, 2003).

Ultimately, a study examining the potential positive impact of the effects of paroxetine-induced changes in endothelium $\mathrm{NO}$ production on $\mathrm{CV}$ outcomes in $\mathrm{MD}$ patients should also be conducted. A beneficial impact of SSRIs on CV outcome was, to a certain extent, supported by recent findings (Glassman et al, 2002; Sauer et al, 2003). The Sertraline Antidepressant Heart Attack Randomized Trial (SADHART) (Glassman et al, 2002), a prospective doubleblind placebo-controlled study examining the effect of treatment with the SSRI sertraline in patients hospitalized for acute myocardial infarction or unstable angina. Although lacking statistical power, this investigation found that there were $20 \%$ fewer serious CV events for patients randomly assigned to sertraline vs placebo. These alterations of indices of NO production in the endothelium and platelets by paroxetine may not, however, generalize to other SSRIs since paroxetine in vitro is the most potent serotonin reuptake inhibitor among SSRIs.

Such studies should include measurements of paroxetine levels at steady state in order to assess possible correlations between paroxetine levels at steady state and paroxetine's peripheral effect of an increase in endothelium production of $\mathrm{NO}$.

In conclusion, this study is of importance in that it further suggests a possible mechanism linking MD and CVD in the form of decreased endothelial and platelet $\mathrm{NO}$ production and a potential beneficial impact of antidepressant treatment in the form of paroxetine on the $\mathrm{CV}$ risk associated with MD. The potential for long-term deleterious CV effects of SSRIs should not, however, be overlooked. For example, paroxetine has been shown to increase low-density lipoprotein levels (Lara et al, 2003b) and can induce severe weight gain (Fava et al, 2000), two major conventional CV risk factors.

\section{ACKNOWLEDGEMENTS}

We would like to acknowledge the University of Alberta Hospital Foundation, the Canadian Institutes of Health Research (CIHR), the Alberta Heritage Foundation for Medical Research, and the Heart and Stroke Foundation for their support. We would also like to thank Lori Zuk, Laurentina Tolvay, Stephen Culver, Cinnamin Lewandiwski, and Rosann Lastiwska at the Clinical Investigation Unit for their assistance and Gail Rauw in the Neurochemical Research Unit for her assistance in the measurement of plasma paroxetine levels.

\section{REFERENCES}

Anderson TJ (2003). Nitric oxide, atherosclerosis and the clinical relevance of endothelial dysfunction. Heart Fail Rev 8: 71-86.

Archer SL (1993). Measurement of nitric oxide in biological models. FASEB J 7: 349-360.

Archer SL, Djaballah K, Humbert M, Weir KE, Fartoukh M, Dall'ava-Santucci J et al (1998). Nitric oxide deficiency in fenfluramine- and dexfenfluramine-induced pulmonary hypertension. Am J Respir Crit Care Med 158: 1061-1067.

Barua RS, Ambrose JA, Eales-Reynolds LJ, DeVoe MC, Zervas JG, Saha DC (2002). Heavy and light cigarette smokers have similar dysfunction of endothelial vasoregulatory activity: an in vivo and in vitro correlation. J Am Coll Cardiol 39: 1758-1763.

Beck AT, Ward CH, Mendelson M, Mock J, Erbaugh J (1961). An inventory for measuring depression. Arch Gen Psychiatry 4: $53-63$.

Blair SN, Haskell WL, Ho P, Paffenbarger Jr RS, Vranizan KW, Farquhar JW et al (1985). Assessment of habitual physical activity by a seven-day recall in a community survey and controlled experiments. Am J Epidemiol 122: 794-804.

Bonetti PO, Lerman LO, Lerman A (2003). Endothelial dysfunction: a marker of atherosclerotic risk. Atheroscler Thromb Vasc Biol 23: 168-175.

Chen LY, Mehta JL (1997). Downregulation of nitric oxide synthase activity in human platelets by nitroglycerine and authentic nitric oxide. J Invest Med 45: 69-74.

Chrapko WE, Jurasz P, Radomski MW, Lara N, Archer S, Le Mellédo J-M (2004). Decreased nitric oxide synthase and plasma nitric oxide metabolites in major depressive disorder. Biol Psychiatry 56: 129-134.

Cicinelli E, Ignarro LJ, Lograno M, Galantino P, Balzano G, Schonauer LM (1996). Circulating levels of nitric oxide in fertile women in relation to the menstrual cycle. Fertil Steril 66 : 1036-1038.

Corti R, Fuster V, Badimon JJ (2003). Pathogenic concepts of acute coronary syndromes. J Am Coll Cardiol 41: 7S-14S.

Drexler H, Hornig B (1999). Endothelial dysfunction in human disease. J Mol Cell Cardiol 31: 1-60.

Fatini C, Sofi F, Gensini F, Gori AM, Fedi S, Lapini I et al (2004). Influence of endothelial nitric oxide synthase gene polymorphism (C894T, 4a4b, T-786C) and hyperyhomocysteinemia on the predisposition to acute coronary syndromes. Am Heart J 147: 516.

Faulx MD, Wright AT, Hoit BD (2003). Detection of endothelial dysfunction with brachial artery ultrasound scanning. Am Heart J 145: 943-951.

Fava M, Judge R, Hoog SL, Nilsson ME, Koke SC (2000). Fluoxetine versus sertraline and paroxetine in major depressive disorder: changes in weight with long-term treatment. J Clin Psychiatry 61: 863-867.

Finkel MS, Laghrissi-Thode F, Pollock BG, Rong J (1996). Paroxetine is a novel nitric oxide synthase inhibitor. Psychopharmacology Bull 32: 653-658.

Freedman JE, Loscalzo J, Barnard MR, Alpert C, Keaney JF, Michelson AD (1997). Nitric oxide released from activated platelets inhibits platelet recruitment. J Clin Invest 100: 350-356.

Freedman JE, Ting B, Hankin B, Loscalzo J, Keaney JF, Vita JA (1998). Impaired platelet production of nitric oxide predicts presence of acute coronary syndromes. Circulation 98: $1481-1486$. 
Glassman AH, O’Connor CM, Califf RM, Swedberg K, Schwartz P, Bigger Jr JT et al (2002). Sertraline treatment of major depressive disorder in patient with acute MI or unstable angina. JAMA 288: 701-751.

Hamilton M (1960). A rating scale for depression. J Neurol Neurosurg Psychiatry 23: 5662.

Joynt KE, Whellan DJ, O'Connor CM (2003). Depression and cardiovascular disease: mechanisms of interaction. Biol Psychiatry 54: 248-261.

Lai C-T, Gordon ES, Kennedy SH, Bateson AN, Coutts RT, Baker GB (2000). Determination of paroxetine levels in human plasma using gas chromatography with electron-capture detection. J Chromatography B 749: 275-279.

Lara N, Archer SL, Baker GB, Le Melledo J-M (2003a). Paroxetineinduced increase in metabolic end products of nitric oxide (NO). $J$ Clin Psychopharm 23: 641-645.

Lara N, Baker GB, Archer SL, Le Melledo JM (2003b). Increased cholesterol levels during paroxetine administration in healthy men. J Clin Psychiatry 64: 1455-1459.

Laroia ST, Ganti AK, Laroia AT, Tendulkar KK (2002). Endothelium and the lipid metabolism: the current understanding. Int J Cardiol 88: 1-9.

Maheda S, Miyauchi T, Kakiyama T, Sugawara J, Iemitsu M, Irukayama-Tomobe $\mathrm{Y}$ et al (2001). Effects of exercise training of 8 weeks and detraining on plasma levels of endothelium-derived factors, endothelin-1 and nitric oxide, in healthy young humans. Life Sci 69: 1005-1016.

Mangos GJ, Walker BR, Kelly JJ, Lawson JA, Webb DJ, Whitworth JA (2000). Cortisol inhibits cholinergic vasodilatation in the human forearm. Am J Hypertension 13: 1155-1160.

Mehta JL, Chen LY, Kone BC, Mehta P, Turner P (1995). Identification of constitutive and inducible forms of nitric oxide synthase in human platelets. J Lab Clin Med 125: 370-377.

Moncada S, Higgs A (1993). Mechanisms of disease: the L-argininenitric oxide pathway. $N$ Engl J Med 329: 2002-2012.

Musselman DL, Ulla MM, Manatunga A, Penna S, Reemsnyder BS, Knight B et al (2000). Platelet reactivity in depressed patients treated with paroxetine. Arch Gen Psychiatry 57: 875-882.

Node K, Kitakaze M, Yoshikawa H, Kosaka H, Hori M (1997). Reversible reduction in plasma concentration of nitric oxide induced by cigarette smoking in young adults. Am J Cardiol 79: 1538-1541.

Plotsky PM, Owens MJ, Nemeroff CB (1998). Psychoneuroendocrinology of depression. Hypothalamic-pituitary-adrenocortical axis. Psychiatr Clin N Am 21: 293-307.

Pollock BG, Laghrissi-Thode F, Wagner WR (2000). Evaluation of platelet activation in depressed patients with ischemic heart disease after paroxetine or nortriptyline treatment. J Clin Psychopharmacol 20: 137-140.

Radomski M, Moncada S (1983). An improved method for washing of human platelets with prostacyclin. Thromb Res Suppl 30: 383-389.

Radomski MW, Moncada S (1993). Regulation of vascular homeostasis by nitric oxide. Thromb Haemost 70: 36-41.

Radomski MW, Palmer RMJ, Moncada S (1987). The antiaggregating properties of vascular endothelium: Interactions between prostacyclin and nitric oxide. Br J Pharmacol 92: 639-646.

Radomski MW, Palmer RMJ, Moncada S (1990). An L-arginine/ nitric oxide pathway present in human platelets regulates aggregation. Proc Natl Acad Sci USA 87: 1788-1792.

Radomski MW, Vallance P, Whitley G, Foxwell N, Moncada S (1993). Platelet adhesion to human vascular endothelium is modulated by constitutive and cytokine induced nitric oxide. Cardiovasc Res 27: 1580-1582.

Rajagopalan S, Brook R, Rubenfire M, Pitt E, Young E (2001). Abnormal brachial artery flow-mediated vasodilation in young adults with major depression. Am J Cardiol 88: 196-198.

Rapaport MH (2001). Prevalence, recognition and treatment of comorbid depression and anxiety. J Clin Psychiatry 62(Suppl 24): 6-10.

Rogers KM, Bonar CA, Estrella JL, Yang S (2002). Inhibitory effect of glucocorticoid on coronary artery endothelial function. Am J Physiol Heart Circ Physiol 27: H1922-H1928.

Roose SP (2003). Treatment of depression in patients with heart disease. Biol Psychiatry 54: 262-268.

Roose SP, Glassman AH, Atria E, Woodring S, Giardina EG, Bigger Jr JT (1998). Cardiovascular effects of fluoxetine in depressed patients with heart disease. Am J Psychiatry 155: 660-665.

Roose SP, Spatz E (1999). Treating depression in patients with ischemic heart disease: Which are the best agents to use and avoid? Drug Safety 20: 459-465.

Rozanski A, Blumenthal JA, Kaplan J (1999). Impact of psychological factors on the pathogenesis of cardiovascular disease and implications for therapy. Circulation 99: 2192-2217.

Rudisch B, Nemeroff CB (2003). Epidemiology of comorbid coronary artery disease and depression. Biol Psychiatry 54: 227-240.

Sauer WH, Berlin JA, Kimmel SE (2003). Effect of antidepressant and their relative affinity for the serotonin transporter on the risk of myocardial infarction. Circulation 108: 32-36.

Serebruany VL, Glassman AH, Malinin AI, Nemeroff CB, Musselman DL, van Zyl LT et al (2003). Platelet/endothelial biomarkers in depressed patients treated with the selective serotonin reuptake inhibitor sertraline after acute coronary events. Circulation 108: 939-944.

Serebruany VL, Gurbel PA, O'Connor CM (2001). Platelet inhibition by sertraline and $N$-desmethylsertraline: a possible missing link between depression, coronary events and mortality benefits of selective serotonin reuptake inhibitors. Pharmacol Res 43: 453-461.

Shimokawa H (1999). Primary dysfunction: atherosclerosis. J Mol Cell Cardiol 31: 23-37.

Sindrup SH, Brosen K, Gram LF (1992). Pharmacokinetics of the selective serotonin reuptake inhibitor paroxetine: nonlinearity and relation to the sparteine oxidation polymorphism. Clin Pharmacol Ther 51: 288-295.

Tsuchiya M, Asada A, Kashahara E, Sato EF, Shindo M, Inoue M (2002). Smoking a single cigarette rapidly reduces combined concentrations of nitrate and concentrations of antioxidants in plasma. Circulation 105: 1155-1157.

Vandivier RW, Eidsath A, Banks SM, Preas II HL, Leighton SB, Godin PJ et al (1999). Down-regulation of NO production by ibuprofen in human volunteers. J Pharmacol Exp Ther 289: $1398-1402$.

Viinikka L (1996). Nitric oxide as a challenge for the clinical chemistry laboratory. Scand J Clin Lab Invest 56: 577-581.

Vonesh EF, Chinchilli VM (1997). Linear and Nonlinear Models for the Analysis of Repeated Measurements. Marcel Dekker: New York.

Wallerath T, Witte K, Schafer SC, Schwartz PM, Prellwitz W, Wohlfart P et al (1999). Down-regulation of the expression of endothelial NO synthase is likely to contribute to glucocorticoidmediated hypertension. Proc Natl Acad Sci USA 96: 13357-13362. 